elm weather-boarding and two Army ruts converted into permanent bungalows. With regard to the latter experiment, results show that no economy is effected by using these huts. Another cottage has walls of clay and gravel, while two single and one pair of cottages are being erected in pisé-de-terre. One of the single pisé cottages is now being roofed-this is the first two-storied pisé house erected in England.

Pisé-de-terre walls are built by ramming nearly dry soil between movable shutters arranged as a temporary mould. The method was known in England a century ago, but had. fallen into disuse, and a large number of investigations have been carried out to determine the best lines for its revival. All soils are not suitable for pisé work, for not only must the particles cohere firmly when rammed and dried, but also there must be no excessive shrinkage in the drying process. Calcium carbonate helps to reduce shrinkage, while organic constituents are particularly liable to shrinkage, and therefore weaken coherence in the soil as a whole. The amount of water present in the soil at the time of use is an all-important factor. Generally speaking, this water should be between 7 per cent. and 14 per cent. of the weight of the dried earth. The most suitable method of shuttering and the best form of rammer have been decided, while experiments are also being made to find the most satisfactory material and method for rendering the exterior face of the wall. Pisé building can be carried out in the winter if there is sufficient protection from severe weather, but consideration of the expenses involved in providing tarpaulins, screens, etc., makes it evident that it is not sound economy to undertake pisé construction in the winter months. When building in pise the foundations have to be of brick or concrete; the pisé work mav be started only at about 9 in. to I $\mathrm{ft}$. above the ground-level. This is an important factor in the consideration of the cost of pisé building, which. however. will probably prove to be a considerably cheaper process than building in brick.

\section{Cotton Growing.}

THE Empire Cotton Growing Committee of the Board of Trade, which presented its first report on cotton growing in the British Empire in lanuary last (Nature, February 26 and March 25), has now published a note on "Future Organisation," which may be regarded as an appendix to the report. While it is merely indicative. of the trend of the Com. mittee's ideas, in that such organisation is subject to the appointment of the director and his staff, it makes the situation more definite by estimating the probable expenditure upon the various branches of work contemplated.

As in the case of the original report. all the organisation proposed is for common service, since the expenditure can bring no direct return, but it should, in the Committee's opinion, indirectly brings about an increase in the cotton supplies. The Committee concludes that in order to carry out the work adequately an annual sum of approximately 200,00ol. ought to be assured. This amount may appear large until we remember that cotton to the value of about $50.000,000$. is imported into this country annually.

The note sketches the proposals for finance and superior organisation, executive work, and the eentral office; for staff abroad; for supplementing staffs of agricultural departments oversea, and pioneering; for education and information; and for commercial handling. In the last case the setting up of semicommercial experimental enterprises is excluded from the scope of the note. Amongst these headings the Conmittec proposes an initial expenditure of $20,000 l$. per annum upon its own research station abroad. It also proposes to provide for a staff of ninety men, including scientific workers and agricultural officers of different grades, for the purpose of supplementing local agricultural department staffs " after full consultation with and on invitation by the local administration."

Under the heading of "Education" the Committee makes proposals which take the initiative in a move towards obtaining co-operation between all the plantusing industries in order to increase the facilities for training men in pure science, later to be of economic value to the various agricultural services abroad. It estimates that university staffs in this country should be increased specially for this purpose by at least four professorships, fifteen lectureships, and six administrative and technical lectureships, together with a provision of twenty post-graduate studentships. The annual cost is estimated at $27,000 l$., of which it is suggested that the rotton industry should contribute $12,000 l$, as its share.

\section{Thermostatic Metal.}

THE British Thomson-Houston Co., Ltd., has sent I. us specimens of a new bimetallic strip for use in thermostatically controlled devices. The strip is prepared by the permanent union over their entire length of two metals with widely differing coefficients of expansion. The union between the two component metals is complete and durable, and the strip may be bent, twisted, or hammered without causing the separation of the metals at any point, and even on heating the bond will not be broken so long as the temperature remains below the melting point of the softer of the two metals. Owing to this permanency of union the metal can be formed into any desired shape, annealed after formation, and safely emploved at any temperature below $500^{\circ} \mathrm{F}$. The component metals do not corrode under ordinary conditions, and may be used in any reasonable situation without fear of deterioration or change in operating characteristics. The amount of deflection obtained is alwavs the same in a strip of given length and thickness for a given temperature change, and consequently the strip provides a trustworthy basis for the operation of any thermostatic device. and may be emploved for work of high precision. The deflection due to temperature change varies inversely as the thickness, directly as the square of the length, and directly as the temperature change. With a strip $A$ in. long, $0.3 \mathrm{I}$ in. wide, and 0.03 in. thick the deflection obtained for a temperature change of $100^{\circ} \mathrm{F}$. is about $0.57 \mathrm{in}$. The force exerted varies as the square of the number of degrees of temperature change and as the square of the thickness, and directlv as the width, and is not affected by changes of length. For a strip of the dimensions above-mentioned the force exerted for $100^{\circ} \mathrm{F}$. change of temperature is about $3.0 \mathrm{z}$. weight, whereas for a strip of the same dimensions but $0 . \mathrm{I}$ in. thick the force exerted is about $24 \mathrm{oz}$. weight. To produce a permanent set in a strin 4 in. long, $0.3 \mathrm{I}$ in. wide, and $0.02 \mathrm{in}$. thick a force of about $7 \mathrm{oz}$. weight would be required. The metal is manufactured in standard sizes ranging from 0.015 in. to 0.25 in. in widths up to 6 in. and lengths up to 36 in. It can, however, generally be supplied cut to widths and leneths to suit the purchaser, and in special cases thermostatic metal parts mav be completely formed to the purchaser's specifications. 